\title{
Validity of Anthropometric Regression Equations for Predicting Changes in Body Fat of Obese Females
}

\author{
DOUGLAS L. BALLOR AND VICTOR L. KATCH \\ Behnke Laboratory for Body Composition Research, Department of \\ Kinesiology, Division of Physical Education, The University of Michigan, \\ Ann Arbor, Michigan 48109-2214
}

\begin{abstract}
$A B S T R A C T$ The validity of ten popular anthropometric percent fat prediction equations for estimating changes in percentage of body fat for obese females was studied. Thirty-one obese females (mean $\pm \mathrm{SEM}$, \%fat $=36.7 \pm$ $1.1 \%$, body mass $=75.6 \pm 1.7 \mathrm{~kg}$, age $=32.8 \pm 1.1$ years) participated in a diet-only, diet-plus-exercise, or exercise-only program. Subjects lost $2.7 \pm 0.3$ fat percentage points and $3.0 \pm 0.3 \mathrm{~kg}$ body mass during the 8-week study. While many of the equations had acceptable validity before and after body mass loss, when applied to the prediction of changes in body fat none of the equations was acceptable. It was concluded that use of anthropometric prediction equations to estimate individual percent fat change scores results in large errors and is not recommended.
\end{abstract}

Anthropometric prediction equations are routinely used in clinical settings to estimate body density $\left(D_{b}\right)$, percent body fat (\%BF), and fat-free mass (FFM). The accuracy of these equations is dependent on many factors including age, gender, body composition status, and statistical considerations (Lohman, 1981). In general, predictive accuracy is reduced when populations differ in age, body mass, fitness level, and $\% \mathrm{BF}$ from those used to derive the original equation (Katch and McArdle, 1973; Katch and Katch, 1980; Lohman, 1981; Pollock et al., 1975).

Most of the published prediction equations have not been adequately cross-validated, and only one has been applied to the prediction of changes in body composition. The purpose of the present study, therefore, was to determine the validity of ten popular body composition prediction equations for estimating changes in body fat of obese females.

\section{MATERIALS AND METHODS Subjects}

Thirty-one women (body mass $=75.6 \pm 1.7$ $\mathrm{kg}, \% \mathrm{BF}=36.7 \pm 1.1$ fat percent units, age $=$ $32.8 \pm 1.1$ years) volunteered to participate in an 8-week diet and/or exercise program. Details regarding the diet and exercise interventions are published elsewhere (Ballor et al., 1988). Briefly, subjects participated in one of three programs: Weight training exercise only $(n=10)$, caloric restriction only ( $n$ $=10$ ), or weight training and caloric restriction $(n=11)$. For the purpose of this paper we report data on the above 31 subjects who underwent an average $3.0 \pm 0.3 \mathrm{~kg}$ body mass reduction over 8 weeks. The body mass loss varied as follows between the groups: Exercise-only $\overline{\mathrm{x}}=-0.5 \pm 0.6 \mathrm{~kg}$, caloric-restriction-only $\overrightarrow{\mathrm{x}}=-4.5 \pm 0.5 \mathrm{~kg}$, caloricrestriction, and exercise $\overline{\mathbf{x}}=-3.9 \pm \mathrm{kg}$.

\section{Body Composition}

Body density was determined by using underwater weighing with a residual lung volume (RLV) correction, as described by Katch et al. (1967). Twelve repeat underwater weighings were made with the subject in the same bent-over seated position used in the determination of RLV. The last five trials were averaged and used to represent the "true" underwater weight (Katch, 1971). RLV was taken as the average of three determinations by using the closed-circuit nitrogen washout method of Wilmore (1969). Body density was converted to \%BF by using the Siri equation (Siri, 1961).

\section{Anthropometry}

Six skinfold (tricep, subscapula, suprailiac, thigh, bicep, and abdominal) and five

Received June 23, 1988; accepted October 25, 1988. 
girth measurements (two abdominal-natural and umbilicus; flexed bicep; forearm; and thigh) were taken, as described by Behnke and Wilmore (1974). All measurements were made in duplicate by the same investigator (V.L.K.) and the average was used in all analyses. To establish reliability, separate replicate measurements were made on ten subjects. All test-retest reliability coefficients were greater than $r=.92$, with the exception of the thigh skinfold, where $r$ $=.81$. None of the standard error of measurements exceeded $\pm 1-3 \%$ of the mean value.

\section{Percent Fat Prediction Equations}

Table 1 presents the ten prediction equations. The iliac skinfold site differed between studies. However, a slightly different iliac skinfold introduces a small but systematic error that is less than the error of the method (Sinning and Hackney, 1986). In the present study, the iliac skinfold was taken slightly superior to the iliac crest along the natural oblique stress lines (Behnke and Wilmore, 1974).

\section{Statistics}

A pairwise t-test was used to determine statistical differences between $\% \mathrm{BF}$ deter- mined by underwater weighing (criterion) and $\% \mathrm{BF}$ obtained by using the different prediction equations (predicted). Linear regression and the standard error of estimate (SEE) were computed between the criterion and predicted $\% \mathrm{BF}$ estimates. SEE was computed by using the following formula: $\mathrm{SEE}=\left(\mathrm{ST} . \mathrm{DEV} . \mathrm{X}\left[1-\mathrm{r}^{2}\right]^{1 / 2}\right)$. Total prediction error (TE) was determined as described by Jackson (1984), where TE $=$ (sum of [Y $\left.\left.\mathrm{Y}^{\prime}\right]^{2} / \mathrm{N}\right)^{1 / 2}$ and $\mathrm{Y}$ is the predicted body density and $\mathrm{Y}^{\prime}$ is the measured body density. All values are reported as mean \pm standard error of the mean (SEM).

\section{RESULTS}

Table 2 presents the results for the analyses prior to body mass loss including the mean \%BF (criterion and predicted), the mean percent fat difference (predicted minus criterion), $\mathrm{r}$ (criterion \% $\mathrm{BF}$ vs. predicted $\% \mathrm{BF}$ ), and total prediction error. The slope, intercept, and SEE are also presented.

Five of the ten mean predicted \%BF (JP Sum 4SF, Sloan, Katch SF + C, Durnin, Pollock) were statistically different from the criterion $\% \mathrm{BF}$. The mean differences ranged from a $2.7 \%$ underestimation (Sloan) to a $1.8 \%$ overprediction (Pollock).

The r's and TE's for the cross validation

TABLE 1. Validated Prediction Equations ${ }^{1}$

\begin{tabular}{|c|c|c|c|}
\hline Investigator & $\mathrm{R}$ & $\begin{array}{c}\mathrm{SEE}^{2} \\
(\% \text { fat })^{3}\end{array}$ & Published Equations \\
\hline $\begin{array}{l}\text { 1. Jackson et al. (1980) } \\
\text { (JP Sum 4SF) }\end{array}$ & 0.85 & 3.8 & $\begin{array}{l}\mathrm{BD}=1.096095-0.0006952 \times \text { Sum } 4 \mathrm{SF}+0.0000011 \times \\
\quad(\mathrm{Sum} 4 \mathrm{SF})^{2}-0.0000714 \times \text { age }\end{array}$ \\
\hline $\begin{array}{l}\text { 2. Jackson et al. (1980) } \\
\text { (JP 4SF + C) }\end{array}$ & 0.86 & 3.7 & $\begin{array}{l}\mathrm{BD}=1.1454464-0.0006558 \times \mathrm{Sum} 4 \mathrm{SF}+0.0000015 \times \\
\quad(\mathrm{Sum} 4 \mathrm{SF})^{2}-0.0005839 \times \mathrm{G}\end{array}$ \\
\hline $\begin{array}{l}\text { 3. Jackson et al. (1980) } \\
\text { (JP Sum 3SF) }\end{array}$ & 0.84 & 3.9 & $\begin{array}{l}\mathrm{BD}=1.0994921-0.0009929 \times \text { Sum } 3 \mathrm{SF}+0.0000023 \times \\
\quad(\text { Sum } 3 \mathrm{SF})^{2}-0.0001392 \times \text { age }\end{array}$ \\
\hline $\begin{array}{l}\text { 4. Jackson et al. (1980) } \\
\text { (JP 3SF + C) }\end{array}$ & 0.85 & 3.8 & $\begin{array}{l}\mathrm{BD}=1.1470292-0.0009376 \times \mathrm{Sum} 3 \mathrm{SF}+0.000003 \times \\
\quad(\text { Sum } 3 \mathrm{SF})^{2}-0.0001156 \times \text { age }-0.0005839 \times \mathrm{G}\end{array}$ \\
\hline $\begin{array}{l}\text { 5. Sloan et al. (1962) } \\
\text { (Sloan) }\end{array}$ & 0.74 & 4.1 & $\mathrm{BD}=1.0764-0.00084 \times \mathrm{Si}-0.00088 \times \mathrm{Tr}$ \\
\hline $\begin{array}{l}\text { 6. Katch \& McArdle (1973) } \\
\text { (Katch SF) }\end{array}$ & 0.77 & 3.7 & $\mathrm{BD}=1.08347+0.0006 \times \mathrm{Tr}-0.00151 \times \mathrm{Sc}-0.00097 \times \mathrm{Th}$ \\
\hline $\begin{array}{l}\text { 7. Katch \& McArdle (1973) } \\
\text { (Katch C) }\end{array}$ & 0.80 & 4.3 & $\begin{array}{l}\mathrm{BD}=1.14465-0.00150 \times \mathrm{Arm}-0.00105 \times \mathrm{Abd}+0.00448 \\
\quad \times \text { Fore }-0.00168 \times \text { Thigh }\end{array}$ \\
\hline $\begin{array}{l}\text { 8. Katch \& McArdle (1973) } \\
\text { (Katch SF + C) }\end{array}$ & 0.78 & 4.5 & $\mathrm{BD}=1.14389-0.00114 \times \mathrm{Sc}-0.00149 \times$ Thigh \\
\hline $\begin{array}{l}\text { 9. Durnin \& Womersley (1974) } \\
\text { (Durnin) }\end{array}$ & - & 5.7 & $\mathrm{BD}=1.1423-0.0632 \times \log 4 \mathrm{SF}$ \\
\hline $\begin{array}{l}\text { 10. Pollock et al. (1975) } \\
\text { (Pollock) }\end{array}$ & 0.78 & 4.1 & $\mathrm{BD}=1.0852-0.0008 \times \mathrm{Si}-0.0011 \times \mathrm{Th}$ \\
\hline
\end{tabular}

${ }^{1}$ Statistics from original studies; $R=$ multiple correlation, $S E E=$ standard error of estimate. Sum $4 \mathrm{SF}=\mathrm{sum}$ of tricep, abdomen, suprailiac, and thigh skinfold thicknesses; Sum $3 \mathrm{SF}=$ sum of tricep, thigh, and suprailiac skinfold thicknesses; $\mathrm{G}=\mathrm{gluteal}$ circumference; Si $=$ suprailiac skinfold; $\mathrm{Tr}=$ triceps skinfold; $\mathrm{Sc}=$ scapula skinfold; Th $=$ thigh skinfold; Arm $=$ upper-arm extended circumference; Abd $=$ ave. of natural and umbilicus circumferences; Fore = forearm circumference; Thigh $=$ thigh circumference; Log $4 \mathrm{SF}=$ natural log of the sum of the tricep, subscapula, suprailiac and bicep skinfold thicknesses.

2SEE calculated from density values when not supplied as percent fat in the original paper.

${ }^{3}$ Percent fat by hydrostatic weighing. 
TABLE 2. Pretest Validity Between Percent Fat Determined Hydrostatically and by Using Anthropometric Prediction Equations

\begin{tabular}{|c|c|c|c|c|c|c|c|}
\hline Equation & $\begin{array}{c}\% \\
\text { fat }\end{array}$ & $\begin{array}{c}\text { Difference } \\
\left(\text { est. }-\mathrm{H}_{2} \mathrm{O}\right)\end{array}$ & $\mathbf{r}$ & $\begin{array}{l}\text { Total } 1 \\
\text { error }\end{array}$ & Slope & Int. & $\mathrm{SEE}^{2}$ \\
\hline $\begin{array}{l}\text { Hydrostatic } \\
\text { Weighing }\end{array}$ & 36.7 & - & - & - & - & - & - \\
\hline 1. JP Sum 4SF & 38.1 & $1.4^{*}$ & 0.88 & 3.3 & 1.118 & -5.39 & 3.0 \\
\hline 2. JP 4SF $+\mathrm{C}$ & 37.4 & 0.7 & 0.89 & 3.1 & 1.259 & -10.38 & 2.9 \\
\hline 3. JP Sum 3SF & 36.8 & 0.1 & 0.85 & 3.2 & 1.096 & -3.63 & 3.3 \\
\hline 4. JP $3 \mathrm{SF}+\mathrm{C}$ & 37.3 & 0.6 & 0.88 & 3.1 & 1.215 & -8.70 & 3.0 \\
\hline 5. Sloan & 34.0 & $-2.7^{*}$ & 0.79 & 4.6 & 0.906 & 5.86 & 3.8 \\
\hline 6. Katch SF & 36.7 & 0.0 & 0.77 & 5.4 & 0.551 & 16.42 & 3.9 \\
\hline 7. Katch C & 37.9 & 1.2 & 0.67 & 5.1 & 0.643 & 12.27 & 4.6 \\
\hline 8. Katch $\mathrm{SF}+\mathrm{C}$ & 38.3 & $1.6^{*}$ & 0.77 & 4.8 & 0.664 & 11.21 & 3.9 \\
\hline 9. Durnin & 38.0 & $1.3^{*}$ & 0.84 & 4.1 & 1.684 & -27.26 & 3.4 \\
\hline 10. Pollock & 38.5 & $1.8^{*}$ & 0.89 & 5.0 & 0.642 & 11.98 & 4.1 \\
\hline
\end{tabular}

1 Error of anthropometric equation in predicting percent fat.

2 Standard error of estimate and is the error of estimation following regression analysis.

* Mean predicted significantly different from hydrostatic weighing, $P<.05$

are remarkably similar to the original R's and SEE's. This attests to the "relative" accuracy of the equations for a one-time assessment of \% $\mathrm{BF}$.

Table 3 presents the results of the analyses following intervention and subsequent body mass loss. Seven of the ten predicted $\% \mathrm{BF}$ were statistically different from the criterion \%BF. Only the JP Sum 3SF, Katch SF, and Pollock equations yielded nonsignificant differences between predicted and criterion \%BF. Even though there was an average $3.0 \mathrm{~kg}$ body mass loss, and a $2.7 \%$ reduction in \% $\mathrm{BF}$, the r's and TE's between predicted and criterion \%BF are very similar to the pretest validity data.

Table 4 presents the validity of the different prediction equations for estimating changes in body composition. Presented are comparisons of the post-minus-pre predicted
$\% \mathrm{BF}$ vs the post-minus-pre criterion \%BF. These values are designated predicted $\% \mathrm{BF}$ change and criterion $\% \mathrm{BF}$ change. Seven of the predicted $\% \mathrm{BF}$ changes were statistically different from the criterion \%BF change. The Katch SF formula predicted the mean changes in $\% \mathrm{BF}$ with no error. The correlations between predicted $\% \mathrm{BF}$ change and criterion \%BF change ranged from $\mathrm{r}=$ .40 to $r=.67$. All of these coefficients are statistically significant. The TE's ranged from 1.5 (JF Sum $3 \mathrm{SF}$ ) to 4.5 (Pollock) fat percent units. The SEE's ranged from 1.3 (five equations) to 1.6 (Katch SF) fat percent units.

\section{DISCUSSION}

Prior to the start of the study, five of the ten prediction equations yielded \%BF estimates that were statistically different from

TABLE 3. Posttest Validity Between Percent Fat Determined Hydrostatically and by Using Anthropometric Prediction Equations

\begin{tabular}{|c|c|c|c|c|c|c|c|}
\hline Equation & $\begin{array}{c}\% \\
\text { fat } \\
\end{array}$ & $\begin{array}{c}\text { Difference } \\
\left(\text { est. }-\mathrm{H}_{2} \mathrm{O}\right)\end{array}$ & $\mathbf{r}$ & $\begin{array}{l}\text { Total } \\
\text { error }\end{array}$ & Slope & Int. & $\mathrm{SEE}^{2}$ \\
\hline $\begin{array}{l}\text { Hydrostatic } \\
\text { Weighing }\end{array}$ & 34.0 & - & - & - & - & & \\
\hline 1. JP Sum 4SF & 35.2 & $1.2^{*}$ & 0.86 & 3.5 & 1.015 & -1.86 & 3.3 \\
\hline 2. $\mathrm{JP} 4 \mathrm{SF}+\mathrm{C}$ & 35.1 & $1.1^{*}$ & 0.86 & 3.4 & 1.123 & -5.53 & 3.3 \\
\hline 3. JP Sum 3SF & 34.5 & 0.5 & 0.89 & 3.0 & 1.146 & -5.69 & 2.9 \\
\hline 4. JP $3 S F+C$ & 35.4 & $1.4^{*}$ & 0.89 & 3.3 & 1.179 & -7.82 & 3.0 \\
\hline 5. Sloan & 31.5 & $-2.5^{*}$ & 0.81 & 4.5 & 0.864 & 6.69 & 3.8 \\
\hline 6. Katch SF & 34.0 & 0.0 & 0.82 & 4.3 & 0.669 & 11.17 & 3.6 \\
\hline 7. Katch $\mathrm{C}$ & 37.0 & $3.0^{*}$ & 0.72 & 5.7 & 0.711 & 7.56 & 4.4 \\
\hline 8. Katch SF $+\mathrm{C}$ & 36.7 & $2.7^{*}$ & 0.82 & 4.9 & 0.714 & 7.78 & 3.6 \\
\hline 9. Durnin & 36.2 & $2.2^{*}$ & 0.85 & 4.4 & 1.524 & -21.32 & 3.3 \\
\hline 10. Pollock & 34.8 & 0.8 & 0.83 & 3.7 & 0.88 & 3.32 & 3.6 \\
\hline
\end{tabular}

\footnotetext{
${ }^{1}$ Error of anthropometric equation in predicting percent fat.

${ }^{2}$ Standard error of estimate in percent body fat units.

* Predicted mean significantly different from hydrostatic mean, $P<.05$.
} 
TABLE 4. Validity of Predicting Changes in Percent Body Fat

\begin{tabular}{|c|c|c|c|c|c|c|}
\hline Equation & $\begin{array}{c}\text { Predicted } \\
\% \mathrm{BF}^{1} \\
\text { change }\end{array}$ & $\begin{array}{c}\text { Criterion } \\
\text { \% } \text { BF }^{2} \\
\text { change }\end{array}$ & Difference $^{3}$ & $\mathbf{r}^{4}$ & $\begin{array}{c}\text { Total }^{5} \\
\text { error }\end{array}$ & $\mathrm{SEE}^{6}$ \\
\hline 1. JP Sum 4SF & -2.9 & -2.7 & 0.2 & 0.64 & 2.1 & 1.3 \\
\hline 2. JP $4 \mathrm{SF}+\mathrm{C}$ & -2.3 & -2.7 & $-0.4^{*}$ & 0.58 & 1.6 & 1.4 \\
\hline 3. JP Sum 3SF & -2.3 & -2.7 & $-0.4^{*}$ & 0.61 & 1.5 & 1.3 \\
\hline 4. JP $3 \mathrm{SF}+\mathrm{C}$ & -1.9 & -2.7 & $-0.8^{*}$ & 0.62 & 1.7 & 1.3 \\
\hline 5. Sloan & -2.5 & -2.7 & -0.2 & 0.67 & 2.0 & 1.3 \\
\hline 6. Katch SF & -2.7 & -2.7 & 0.0 & 0.40 & 3.6 & 1.6 \\
\hline 7. Katch C & -0.9 & -2.7 & $-1.8^{*}$ & 0.62 & 2.8 & 1.4 \\
\hline 8. Katch $\mathrm{SF}+\mathrm{C}$ & -1.6 & -2.7 & $-1.1^{*}$ & 0.64 & 2.5 & 1.3 \\
\hline 9. Durnin & -1.8 & -2.7 & $-0.9^{*}$ & 0.65 & 1.7 & 1.3 \\
\hline 10. Pollock & -3.7 & -2.7 & $-1.0^{*}$ & 0.45 & 4.5 & 1.5 \\
\hline
\end{tabular}

${ }_{1}^{1}$ Mean post-minus-pre predicted percent fat.

2 Mean post-minus-pre criterion percent fat.

${ }^{3}$ Mean (post-minus-pre predicted percent fat) - (post-minus-pre criterion percent fat)

${ }^{4}$ Correlation between post-minus-pre predicted percent fat vs. post-minus-pre criterion percent fat.

5 Error of anthropometric equation in predicting percent fat.

${ }^{6}$ Standard error of estimate in percent fat units.

*Criterion significantly different from predicted, $P<.05$.

the criterion \%BF. This increased to seven of ten equations following body mass loss.

While several authors have shown reduced prediction validity with the obese (Barrows and Snook, 1987), formerly obese (Barrows and Snook, 1987; Scherf et al., 1986), and female athletes (Sinning and Wilson, 1984), only one other study has reported the validity of percent body fat prediction before and after body mass loss (Barrows and Snook, 1987). Barrows and Snook (1987) reported the validity of nine different regression equations on 15 obese females who lost an average of $20.5 \mathrm{~kg}$ over a 4-6-month duration. They reported preintervention correlations between predicted and criterion \%BF which ranged from $r=.22$ to $r=.69$. After body mass loss seven of the nine correlations were lower. Our data are similar. However, they based their conclusion that regression equations were not valid for measuring changes in $\% \mathrm{BF}$ without analyzing the $\% \mathrm{BF}$ change correlations, as we have done. Also, since they did not measure residual lung volume, their data must be interpreted with caution since the error associated with predicting residual lung volume reduces the validity of the criterion \% $\mathrm{BF}$ and thus lowers the correlations between the criterion and predicted values (Katch and Katch, 1980).

While on a mean basis it is possible with some degree of accuracy to predict changes in body fat with prediction equations by using skinfolds and/or girths, on an individual basis none of the prediction equations is acceptable. This conclusion is based upon the low correlations and high TE's for the change scores (Table 4).

There are several reasons for the lack of validity in predicting body composition changes by using anthropometric measures. Measurement error exists in both the determination of skinfold thickness and girths (Katch and Katch, 1980) as well as in the ascertainment of body density (Lohman, 1981). These measurement errors reduce the correlation between the criterion \% $\mathrm{BF}$ change and predicted $\% \mathrm{BF}$ change leading to an increased TE (Table 4).

Furthermore, changes in fat-free mass are not necessarily associated with concomitant changes in skinfold or circumference measures. For example, the biceps flexed circumference of the caloric-restriction-plusexercise and exercise-only groups increased by $0.2 \pm 0.2$ and $1.6 \pm 0.2 \mathrm{~cm}$ and decreased by $1.0 \pm 0.3 \mathrm{~cm}$ for the caloric-restrictiononly group. Prediction equations which use the biceps flexed circumference as an estimate of upper-arm muscle mass would yield an increase in muscle mass for the exerciseonly group, no change for the caloric-restriction-plus-exercise group, and a decrease for the caloric-restriction-only group. In actuality, quantifying the muscle area of the upper arm via X-ray (Ballor et al., 1988) revealed no change in upper-arm muscle area for the caloric-restriction-only group and equivalent increases for the exercise-only and caloric-restriction-plus-exercise group. Circumference measurements are a summation of skinfold thicknesses and muscle masses, and changes in circumference may be a 
result of changes in skinfold thickness and/or muscle mass. Similarly, skinfold thicknesses, while yielding an estimate of subcutaneous fat, do not necessarily reflect alterations in the underlying muscle structure. For example, the sum of five skinfolds (subscapula, triceps, thigh, abdomen, and suprailiac) increased by less than $0.3 \%(0.5$ $\mathrm{mm}$ ) following training for the exercise-only group, suggesting (as determined via skinfold estimation) no change in \%BF. How ever, this group increased their fat-free mass by $1.1 \pm 0.3 \mathrm{~kg}$ and decreased their $\% \mathrm{BF}$ by $1.2 \pm 0.4$ fat percent units (hydrostatic weighing). Thus, the type of intervention may affect the ability of anthropometric prediction equations to predict $\% \mathrm{BF}$ change.

As had been previously pointed out (Katch and Katch, 1980), the practice of predicting \%BF from anthropometric data is a dubious procedure and attempting to predict changes in body fat is even more hazardous, as the present data clearly indicate. The clinician confronted with the need to monitor \%BF changes in subjects undergoing intervention has a particular dilemma. It is our opin. ion, based on the data, that individuals who are losing body mass would be better served by monitoring changes over time for such variables as fatfolds, girths, and girth derivatives such as the recently introduced ponderal somatogram (Katch et al., 1987) than by using anthropometric prediction equations to estimate changes in $\% \mathrm{BF}$. We are convinced that the preoccupation with predicting changes in \% $\mathrm{BF}$ is scientifically not justified and must await newer methodology or better-validated methods to warrant use.

In conclusion, the results of Barrow and Snook (1987) and the present study suggest that prediction methodology, using skinfolds, girths, or a combination of girths and skinfolds should not be used to predict individual changes in $\% \mathrm{BF}$.

\section{LITERATURE CITED}

Ballor DL, Katch VL, Becque MD, and Marks CR (1988) Resistance weight training during caloric restriction enhances lean body weight maintenance. Am. J. Clin. Nutr. 47:19-25.
Barrows K, and Snook JT (1987) Effect of a high-protein, very-low-calorie diet on body composition and anthropometric parameters of middle-aged women. Am. J. Clin. Nutr. 45:381-90.

Behnke AR and Wilmore JH (1974) Evaluation and Reglation of Body Build and Composition. Englewood Cliffs, New Jersey: Prentice-Hall, pp. 223-224.

Durnin JVGA, and Womersley J (1974) Body fat assessed from total body density and its estimation from skin fold thickness: Measurements on 481 men and women aged from 16 to 72 years. Br. J. Nutr. 32:77-96.

Jackson AS, Pollock ML, and Ward A (1980) Generalized equations for predicting body density of women. Med. Sci. Sports Exerc. 12(3):175-182.

Jackson AS (1984) Research design and analysis of data procedures for predicting body density. Med. Sci Sports Exerc. 16(6):616-620.

Katch FI, Michael ED, and Horvath SM (1967) Estimation of body volume by underwater weighing: A de scription of a simple method. J. Appl. Physiol. 23 811-813.

Katch FI (1971) Pre- and post-test changes in the factors that influence computed body density changes. Res. $Q$. 42(3):280-285.

Katch FI, and McArdle WD (1973) Prediction of body density from simple anthropometric measurements in college-age men and women. Hum. Biol. 45(3):445-454.

Katch FI, and Katch VL (1980) Measurement and predic tion errors in body composition assessment and the search for the perfect prediction equation. Res. Q. Exerc. Sport 51(1):249-260.

Katch FI, Behnke AR, and Katch VL (1987) The ponderal somatogram: Evaluation of body size and shape from anthropometric girths and stature. Hum. Biol. 59/3): 439-458.

Lohman TG (1981) Skinfolds and body density and their relation to body fatness: A review. Hum. Biol. 53(2) $181-225$.

Pollock ML, Laughridge EE, Coleman B, Linnerud AC, and Jackson A (1975) Prediction of body density in young and middle-aged women. J. Appl. Physiol. 38(4):745-749.

Scherf J, Franklin BA, Lucas CP, Stevenson D, and Rubenfire M (1986) Validity of skinfold thickness measures of formerly obese adults. Am. J. Clin. Nutr. 43:128-135.

Sinning WE, and Wilson JR (1984) Validity of "general. ized" equations for body composition analysis in women athletes. Res. Q. Exerc. Sport 55(2):153-160.

Sinning WE, and Hackney AC (1986) Relationships among skinfold measures of lower torso and abdominal fat in athletes. Res. Q. Exerc. Sport 57(4):334-338.

Siri WE (1961) Body composition from fluid spaces and density. In J Brozek and A Henshel (eds.): Techniques for Measuring Body Composition. Washington DC: National Academy of Sciences, pp. 223-244.

Sloan AW, Burt JJ, and Blyth CS (1962) Estimation of body fat in young women. J. Appl. Physiol. 17(6): 967-970.

Wilmore JH (1969) A simplified method for determination of residual lung volumes. J. Appl. Physiol. 27(1): $96-100$ 